This is an Accepted Manuscript of an article published by Springer in Res Publica 12 March 2015. The final publication is available at Springer via http://dx.doi.org/10.1007/s11158-015-9270-5.

\title{
Producing solidarity, inequality and exclusion through insurance
}

20 January 2015

Turo-Kimmo Lehtonen*

Professor of Sociology

School of Social Research and Humanities

Linna 5064

FIN-33014 University of Tampere

Finland

turo-kimmo.lehtonen(ät)uta.fi

http://blogs.helsinki.fi/tklehton/homepage/
Jyri Liukko

Senior Researcher

Finnish Centre for Pensions

FIN-00065 Eläketurvakeskus

Finland

jyri.liukko(ät)etk.fi

*corresponding author 


\title{
Producing solidarity, inequality and exclusion through insurance
}

\begin{abstract}
The article presents two main arguments. First, we claim that in contemporary societies, insurance enacts peculiar kinds of solidarities as well as inequality and exclusion. Especially important in this respect are life, health, disability and old age pension insurance, both in compulsory and voluntary forms. Second, the article maintains that the ideas of solidarity, inequality and exclusion are transformed by the machinery of insurance. In other words, the concrete ways in which insurance relations are practically arranged have an effect on the ways in which the related moral and political concepts are perceived. We elaborate on three different forms of insurance solidarity, which we call chance, risk and income solidarity. The existence of multiple forms of solidarity relevant to insurance is significant because practices of insurance require decisions concerning what kind of solidarity is emphasised, when it is emphasised, and on what grounds. Moreover, what is solidarity for some can entail exclusion and inequality for others. Showing these internal tensions within insurance practice underlines the inherently political and moral nature of insurance.
\end{abstract}

\section{Keywords}

Insurance, Solidarity, Risk, Inequality, Exclusion 


\section{Introduction}

Historically, insurance practices have been conceived as having various functions. In addition to serving as a tool for securing economic activity, insurance has been a means for boosting local or national mutuality (Ericson et al. 2003, 59; Zelizer 1983), a primary technology for organising welfare regimes (Barr 2001; Beveridge 1942; Ewald 1986; Lobo-Guerrero 2011; O’Malley 2004; Rosanvallon 1995) and a way of capitalizing the vital potentiality of human lives; that is, insurance can make health and human mortality objects of market action (French and Kneale 2009; Lobo-Guerrero 2014). This variability has led François Ewald (1986) to discuss different 'insurance imaginaries' and the flexibility of insurance. Nonetheless, we claim here that some elements of exclusion, inequality and solidarity can be found in all insurance related to life or health risks. This is notwithstanding that the forms of solidarity, inequality and exclusion vary substantially, and the emphases on them differ in specific insurance arrangements and regimes. The main aim of this work is to clarify how and why this variation emerges. Our secondary aim is to develop a conceptual distinction between chance solidarity (the basic idea of risk sharing), risk solidarity (premium equalisation) and income solidarity (income equalisation). By studying the differences between chance, risk and income solidarity, it is possible to illuminate why debates concerning fair underwriting and insurance practices are riddled with moral and political controversy. The background of the paper is given by our earlier, more empirical work on insurance (e.g. Lehtonen 2014; Lehtonen and Liukko 2010; Liukko 2010). Through this research, we have come to realise that within the field, relevant actors often encounter the questions of solidarity, exclusion and inequality. Yet, a systematic understanding of what is at stake and when in regard to these themes is lacking. Therefore, this paper aims to meet the need for conceptual clarification.

We argue that insurance produces, or at least organises, relations of responsibility by implementing certain forms of solidarity, inequality and exclusion. But is it not more a case of insurance either just reflecting if not reproducing pre-existing social relations? Of course the answer is partly yes. Nonetheless, in emphasising the productive side of insurance we want to say two things. First, solidarity, inequality and exclusion can be the end products of insurance; something that would not come into being in these precise forms without the insurance machinery. Second, the ideas of solidarity, inequality and exclusion are transformed through this machinery. In other words, the concrete ways in which insurance technologies are practically used have an effect on the ways the related moral and political concepts are perceived. Importantly, insurance 
economics, technical means of calculating probabilities and the general statistical 'style of reasoning' (Hacking 1990) are in a two-way relationship with moral and political rationalities.

The rest of the paper proceeds as follows. In the second section, we introduce specifics that distinguish insurance from most forms of saving. We see this distinction as important for understanding the multipolar nature of insurance and the forms of solidarity that rely on this multipolarity. Then, we move on to discuss the sharing of responsibility in insurance arrangements, which helps define the differences between chance, risk and income solidarity more precisely. The final sections of the article deal with issues of fairness, inequality and exclusion between individuals and groups in insurance relations.

\section{Multipolarity of risk pooling: Why insurance is different from saving or gambling}

Insurance is a practice of prudence and foresight: when an individual takes out an insurance policy or is insured through social insurance, she is forced to put resources aside now so they are available in the future. Thus, there is an element of saving present in all insurance. However, the idea of insurance as personal saving can conquer the whole imaginary governing the insurance relationship. That is, when an accident takes place, people are happy to 'get their money back' at long last. In the case of private insurance, it is not unheard of for people who have paid insurance fees for a long time to think that it is morally acceptable to exaggerate the losses and claims when the insured event does take place, and the insurance instrument is finally 'really' used. Of course, insurance companies know this. Not only do they suspect such behaviour, but the industry conducts research on incentives for moral hazard and on clients' moral expectations and ideas. They also use elaborate information technology systems to detect fraudulent claims. Yet, it can be difficult and costly to prove when claims are dishonest. Often, it is much easier for the companies to pay the indemnities without asking, and cover the costs through higher insurance premiums (Ericson and Doyle 2004; Lesch and Baker 2013). Thus the clients can be right in suspecting that the insurance fees do not really reflect the correct price of an accident or the likelihood of it taking place. Therefore, on both sides of the insurance relationship, mistrust and fear of moral hazard are understandable.

Moral hazard and greed can indeed colour an insurance relationship. However, to understand that insurance cannot be reduced to a straightforward situation of two individual actors (of which either one can be an institution) playing against one another, it is useful to make a conceptual distinction between insurance and simple saving. To begin with, saving can be done individually 
or, in the case of bank saving, in a bipolar relationship between a client and service provider. In contrast, insurance technology always presupposes a pool of insureds. Insurance is always multipolar. It is a means with which a group of people join their resources to face future uncertainties.

An objection could be made that if the insurance company has a table of risk at its disposal, it can apply this table to one client without needing to assemble a pool. But if there is no pool and the risk is only divided between one client and the company, it is not really spread. Instead, the client and the company just gamble. Although informed by the table of risk, they both bet on the likelihood of an accident; one side wins and the other side loses. ${ }^{1}$

In the case of insurance, actuarial calculations and the spreading of risk are meant to guarantee that the company cannot lose. But also from the insured's point of view, it is the spreading of risk that makes the insurance instrument much more efficient than plain saving. If a person wants to save individually for the costs of a potential future harm, he or she should put aside the whole sum that will cover the harm rather than use the money saved for other, perhaps more immediately gratifying purposes. In contrast, in the case of insurance, it is sufficient that the pool can cover the sum needed for the insurance event, as individual participants cover only tiny parts of the cost, which is their fair share of the risk. Of course, the insurance fee is an expenditure, but it is usually small compared to the size of a potential insurance event.

Finally, in contrast to saving, in a pure insurance relationship, the insured does not expect to get his or her money back. This is linked to the efficiency of the insurance instrument: most of the insurance payments go to covering someone else's harm (Baker 2002, p. 36). In more technical terms, all participants of the pool are involved in covering the economic damage that the pool as a whole encounters. If the neoclassical economics commonplace definition of saving as 'delayed consumption' is applied, insurance is clearly about something else. An insured does not know whether she will someday (be able to or have to) use the money put aside in the form of insurance fees. The premiums paid are not individuals' own money, but future liabilities for the whole insurance pool. ${ }^{2}$

\footnotetext{
1 This was the case in some of the first forms of commercial (marine) insurance. An affluent banker or 'insurer' lent money for traders with high interest rates and promised to compensate the losses from his own assets, in case of misfortune.

2 The term risk pool can have several meanings. Sometimes it is used narrowly to emphasise the pooling of similar risks so that a wider insurance collective can include several risk pools with distinct risk profiles. Other times, the term is used in joint arrangements where several insurance companies have decided to share the costs of especially rare and costly risks, such as natural catastrophes. In this article, we use the concepts of insurance pool and risk pool broadly, referring just to the basic idea of risk sharing inherent in all insurance.
} 
To sum up, there are at least four aspects which differentiate insurance from saving and which are all related to the multipolarity of insurance: in contrast to saving, insurance implies the pooling of resources, the spreading of risks and, consequently, a more efficient management of resources for utilisation against potential future harm; and, in most cases, the insureds are not supposed to get their money back. There is always a risk of losing the paid premiums or social insurance contributions.

As we claim in this article, the multipolar constitution of pools is a core element of insurance solidarity. Why is it, then, that people tend to regard insurance as a bipolar relationship between a client and service provider, as if it were just another form of saving? This has partly to do with marketing. Although historically, solidarity and mutuality have been core ideas in the establishment of insurance companies and even in their advertising, more recently in the Western countries, these themes have been mostly disregarded (Lehtonen and Liukko 2010). In other words, when selling policies, companies tend to accentuate the bipolarity of the insurance relationship and the high quality of their operations instead of the constituent multipolarity behind the insurance product. In addition, many life insurance policies are composites of multiple products, including strong or even dominant savings components. Especially if the marketing of a product emphasises the future earnings in combination with underscoring the company's relationship with its individual clients, it is no wonder that neither customers nor insurance providers perceive how and why insurance would imply questions of solidarity, exclusion and the gathering of the collective. Nonetheless, it is this side of insurance that we concentrate on in the rest of the paper. Our claim is that although the questions concerning solidarity and exclusion might not be apparent even to the relevant actors, they are fundamental to the way in which insurance functions as a social technology.

\section{Chance solidarity and actuarial fairness}

Although contemporary forms of insurance have emerged out of the liberal tradition of emphasising individual prudence and foresight, they create a displacement within this tradition. This is one of the central points of Ewald's magnum opus L'Etat providence (1986), which is a study of the development of the French 'insurance society' and welfare state. Ewald discusses how insurance became a crucial mechanism able to link individual and joint responsibility in a novel way. While not doing away with a conception of individual responsibility, both public and private insurance arrangements transfer responsibility to a pool whose members all carry the 
responsibility for the harmful events that any of the pool members encounter. Moreover, it is not a question of whether a person feels the responsibility; rather, insurance is a technical means, a combination of risk technologies and contracted liabilities with which responsibility relationships are arranged.

While insurance is fundamentally about sharing responsibility, this sharing is strictly limited. To begin with, its extension is defined by the insurance contract or political decision. Both in social and private insurance, the insurance cover only applies to predefined cases and often only up to the predefined amount of monetary compensation. Even more importantly, while participation in a risk pool is about sharing responsibility, once the fees are paid, the insureds are free of responsibility, even for the harms they personally run up against. ${ }^{3}$ All at once, insurance is about creating possibilities for responsibility and about socialising responsibility (Baker 2002, p. 33-34). Through the payment, responsibility is transferred to the company or the state and, by implication, to all policyholders. The insurance fee is the price for which the insurer will carry the responsibility.

The two features of contractuality and the sharing of responsibility are the cornerstones of the peculiar type of solidarity presented by insurance. Before going into greater detail on this peculiarity, it is useful to look at what insurance solidarity is not. Clearly, an insurance pool does not depend on its members having sentimental bonds or sharing values (other than on a very general level), aspects often listed as constituent characters of solidarity (Bayertz 1998; May 1996; Spicker 1991; Stjernø 2004). ${ }^{4}$ Similarly, insurance is not a case of either mechanic or organic forms of solidarity, as described by Emile Durkheim (1984). As a technology that relies on the use of contract law, statistical and actuarial risk analyses, marketing tools, and overall functioning of market capitalism, insurance is far from spontaneous reciprocity implied by mechanic solidarity. Yet, it is also far from organic solidarity. Organic solidarity is based on an unplanned division of labour, which follows its immanent rules of organisation and which does not need to be explicated to exist. In contrast, insurance solidarity is a consciously and reflectively planned, institutionalised and regulated way of organising the sharing of responsibility. This notwithstanding that, perhaps for the majority of its users, the more specific technicalities of insurance pooling remain a 'black box'.

\footnotetext{
${ }^{3}$ Of course, this general statement can be somewhat qualified by noting that in many cases, policyholders are not completely free of financial responsibility, as insurance policies may include different kinds of deductibles or co-payments for preventing overuse and moral hazard.

${ }^{4}$ This is not to say that sentimental bonds or shared values cannot play a role in insurance; historically, especially in the establishment of mutual insurance companies, they have been crucial.
} 
We deem the element of responsibility sharing, constitutive for all insurance pools, as especially important for insurance solidarity. There is a fundamental uncertainty as to who will encounter harm and who, consequently, will benefit most from the existence of the insurance pool. The ignorance regarding who is the future beneficiary constitutes insurance as the realm of chance solidarity (Thiery and Van Schoubroeck 2006): participants take responsibility for each other in the face of chance, not knowing in advance who gets paid.

The concept of chance solidarity is very important for understanding what kind of solidarity is inherent in insurance. Yet, it does not give any answer to the key question of justice: What is a fair way to share the costs of the insurance pool? Within the insurance business, the term actuarial fairness is used for the idea that all members of the insurance pool should pay according to the risk they constitute for the pool. In other words, the ratio between risk and premiums should be exactly the same for all members of the pool. ${ }^{5}$ Those with lower risk also pay less. Behind this idea, there is the technical capacity to calculate levels of risk for categories of insureds. If taken to its extreme, risk classification could mean that each insured could constitute his or her own separate risk class. Still, in most forms of insurance, whether private or social, premium levels are allocated to large groups of people, or risk classes.

Thiery and Van Schoubroeck (2006) connect solidarity rather straightforwardly with actuarial fairness; that is, they link the concept of chance solidarity with the requirement for actuarially and economically optimal risk classification. To us, such a position does not seem warranted for three reasons. First, chance solidarity can be defined so that it is not dependent on risk calculation or actuarial information. Rather, it is the very basic form of insurance solidarity in that it is neutral as to the question of risk classification; never mind the way in which the precise pooling is done. In the face of chance, there is a degree of solidarity in that no one knows what the future brings; that is, who faces harm and gets paid by the pool. Even those with extremely low risk can have bad luck. In this way, chance solidarity is related to the fundamental contingency and uncertainty of life. This makes understandable our second, more historical, reservation towards linking chance solidarity to actuarial fairness. Namely, it can be claimed that chance solidarity is also the original form of insurance solidarity; it was present in insurance arrangements before the concept of statistical risk was invented and the related actuarial practices were developed. Finally, in relation to actuarial fairness, chance solidarity can take two extreme forms and every form in between, reflecting moral and political agreements. Solidarity that equalises premiums by consciously ignoring risk differences, and solidarity that differentiates

\footnotetext{
${ }^{5}$ For a recent overview and discussion of the concept, from a philosophical point of view, see Landes 2014.
} 
premiums according to risks. All in all, we believe the concept of chance solidarity is important but want to loosen its link to the concept of actuarial fairness.

\section{Risk solidarity and income solidarity}

It might seem paradoxical, but, although chance solidarity is omnipresent in insurance, its significance is limited when attempting to understand insurance solidarity. This seems to be the key intuition behind Thiery and Van Schoubroeck's efforts to contrast the concept of chance solidarity with the concept of subsidiring solidarity. They define the latter in the following manner:

'Groups that, despite insurers' efforts, do not consist of members with a comparable risk profile, give rise to the phenomenon of "subsidizing solidarity". In this situation, a person with a certain risk profile pays for the amount of loss of persons bearing higher loss expectancy.' (Thiery and Van Schoubroeck 2006: 196)

As we have noted in an earlier text, subsidizing solidarity comes in two distinct forms. These are subsidizing risk solidarity and subsidizing income solidarity (Lehtonen and Liukko 2011). The first of these is defined in the following way: '[...] the less the risks and fees correspond, the more subsidizing there is that is favourable to those with high risk' (Lehtonen and Liukko 2011, p. 39). In contrast to subsidizing risk solidarity, subsidizing income solidarity means that the less the payments and benefits correspond, the more subsidizing there is in the form of income redistribution.

The intuition behind the distinction between chance solidarity and subsidizing solidarity is important. Not only does it make apparent the existence of a plurality of forms of solidarity in insurance, but it also clarifies why that which is deemed fair in an insurance relationship can be judged on grounds that can be difficult to align. Nonetheless, in contrast to our earlier text, we now claim that making the distinction in terms of chance versus subsidization does not go to the crux of the matter.

In all forms of insurance where there is little or no differentiation between pool members' individualised risk categories, those with low risk de facto subsidize those with high risk; yet, pool members can have no idea whether such subsidizing is actually taking place and who is subsidizing whom. This is the usual situation. Although risk classification is applied in life, health and disability insurances in particular, normally it is on a relatively broad level; the industry is still quite far from being able to constitute risk categories for individual insureds (although this might 
be the tendency). More importantly, is it not the case that, in the end, the person who gets paid by the insurance pool is always subsidized by the other pool members, regardless of whether risk classification has been applied or not? Therefore, subsidizing solidarity seems to overlap fundamentally with chance solidarity, and the distinction is unclear.

While retaining some key intuitions and formulations by Thiery and Van Schoubroeck (2006) and our own earlier paper (Lehtonen and Liukko 2011), but modifying their terms, we arrive at a tripartite distinction between fundamental forms of insurance solidarity.

Chance solidarity refers to the basic sharing of responsibility in the face of uncertainty that is achieved by an insurance pool. At its core, this form of solidarity is indifferent to the availability of actuarial information on risk or knowledge concerning the pool members' financial situations.

Risk solidarity has to do with the equalisation of pool members' risk premiums. Crucial for making risk solidarity a case of solidarity is that it takes into account the actual or virtual availability of risk information for the purpose of acting against it, that is, evening out the risk differences between the pool members. Therefore, risk solidarity is contradictory to the idea of actuarial fairness (that is, the idea that the amount of risk and the price of the insurance policy should have a positive and close correlation).

Income solidarity has to do with the equalisation of pool members' economic positions in view of their income profiles. Similarly to chance solidarity, income solidarity does not have a necessary relationship with technical risk calculations. Rather, the knowledge concerning pool members' economic resources, and the effort of levelling differences in these resources is what matters.

This tripartite distinction is useful because it clarifies the kinds of solidarities that are relevant for an insurance pool, but also makes it easier to analyse which themes constitute political and moral tensions when the question of fairness arises. It is noteworthy that basic chance solidarity does not give rise to political or moral debate. The big issues concern positions taken towards questions of risk and income solidarity, and the ways in which these are stressed and balanced in particular insurance assemblages. Let us look at a couple of examples of the kinds of tensions that are relevant here.

Whether the practice of risk classification is seen as fair has varied much during the past century. In the case of car insurance, for instance, not many would object to an 18-year-old male who 
drives a powerful sports car and has several speeding fines paying more than those motorists with track records of driving carefully in safe family cars. In this case, actuarial fairness is seen as fair indeed, and neither risk nor income solidarity are practised. The case of social insurance is different. Historically, welfare systems have been built on the promise that everybody is equally taken care of, and so risk categories have not been emphasised. The idea of fairness and solidarity has been linked with ideas of equalisation. Depending on the kind of social insurance, both income solidarity and risk solidarity are often practised. In contrast, the idea of actuarial fairness presupposes that people can, to a degree, be held responsible for the risk they transfer to the pool. ${ }^{6}$ Pierre Rosanvallon (1995), among others, noted that as the actuarial means for creating risk categories have developed, it has become ever clearer to the members of welfare states that these do not operate according to the idea of actuarial fairness. ${ }^{7}$ Although the well-todo members of society face lower risks regarding health or unemployment, they pay higher fees in the forms of taxes and social insurance contributions. According to Rosanvallon, awareness of this relationship has tended to erode the willingness of the middle classes to contribute to the expenditures of the welfare state.

Another example is related to insurance and gender. For several decades in most Western European countries, it has been customary that women pay lower life insurance fees than men due to the lower mortality among women. For car and motor liability insurance, women have also been regarded as 'better risks' and, accordingly, have paid lower prices for their policies, as the harm caused by female drivers tends to be economically less serious than that inflicted by males. Therefore, in these cases, instead of equal premiums on the basis of either income or risk solidarity, it has been deemed reasonable to follow the principle of actuarial fairness. In March 2011, the Court of Justice of the European Union made a decision to end this practice, as it was seen to violate an earlier directive that prohibits all discrimination based on sex in the access to goods and services. This decision implies that women now have to practise risk solidarity in relation to men (it might be worth mentioning, however, that the terminology of solidarity is not explicitly used in the decision). Risk-differentiated chance solidarity or actuarial fairness is not enough. The moral idea behind the decision is that in the face of risk, a person should not be held responsible for an inherited quality, such as gender. Similar arguments have been used to criticise the utilisation of disability as a risk classification criterion in private life and health

\footnotetext{
${ }^{6} \mathrm{It}$ is noteworthy, however, that the concept of actuarial fairness does not imply positions taken on the question of whether risk levels are self-inflicted. The question of responsibility is completely transformed when it is related to individual, voluntary action. ${ }^{7}$ However, as Beveridge (1942, p. 13) noted, '[t]hough the State, in conducting compulsory insurance, is not under the necessity of varying the premium according to the risk, it may decide as a matter of policy to do so.'
} 
insurance contracts. However, disability is still considered an acceptable reason to discriminate between insureds, regardless of the critical political discussion.

Finally, the question of whether insurance companies can consider predictive genetic information of insurance clients' susceptibility to certain diseases has been a hot issue for quite some time (Liukko 2010; Van Hoyweghen 2007). More than 20 European countries have ratified the Council of Europe's Convention on Human Rights and Biomedicine, which prohibits genetic testing as a condition for entering into an insurance contract. In addition to this international convention, some European countries have enacted much stricter national prohibitions for insurers by restricting the use of pre-existing test results (Knoppers et al. 2004, p. 185). Behind these conventions is the ethical position according to which no one should be punished for a condition to which he or she cannot have actively contributed, and even more importantly, the general requirement for privacy and equal rights. As in the previous case, the tension between actuarial fairness and risk solidarity comes down to what is thought to be the scope of voluntary action and the ensuing idea of responsibility.

An unintended consequence of the prohibition of discrimination against inherited qualities has been the growing acceptance of discrimination against so-called 'lifestyle risks', such as drinking, drug use and dangerous occupations (Van Hoyweghen et al. 2007). This is a strong tradition in insurance thinking that has been accentuated recently, according to some scholars (French and Kneale 2009). The tricky thing is that, as social scientists would say, it is not always clear to what extent a person can be held responsible for his or her lifestyle, social milieu or area of residence—all of which are criteria for separating 'good' risks from 'bad'.

\section{Solidarity with an individual or the insurance pool}

The need for security brings insureds together through the mediation of the insurance provider. As discussed above, the most efficient way to obtain this security is to pool resources. Once the resources are pooled, insureds have a common interest in guarding the assembled funds. However, this common interest can lead to tensions between members of the pool. In most social scientific literature, the recognised tension is that of moral hazard: situations where individuals lose their incentives to prevent losses of the whole pool, and where they might even 
have incentives for fraudulent action. ${ }^{8}$ Yet, this is only a special case of the more fundamental tension within the insurance pool, which Tom Baker sums up:

'Payment is almost always in the interest of individuals who have suffered losses, but in the aggregate those losses may overwhelm the insurance trust fund. [...]. Thus, the insurance relationship is also a relationship of balance in which the insurance company mediates between those currently in need and those who may be in need in the future.' (Baker 1994, p. 1402)

This relationship of balance can also be conceptualised in terms of solidarity. That is to say, regardless of the form of solidarity, there can be a tension between solidarity towards individual insureds and towards the community of insureds. The members of the pool can be in solidarity with each other while not in solidarity with the one member who is claiming indemnities and wants the company to hold its promise to pay in case of accident (Baker 1994, pp. 1396, 1401). This situation leads to a duality in the role of an insurance company and of the welfare state as a huge insurance provider. On the one hand, there is the role of trustee of the insurance 'trust fund', and on the other the role of protector and 'servant' of individual insureds in need. These two roles easily clash.

The analysis is complicated because, in the end, it is also in the long-term interest of the other insureds that the company dutifully pay for every legitimate claim, although this might generate losses for the insurance pool in the short term. As Baker (1994, p. 1429) points out, from this perspective, a claimant litigating with the company over the payments, and thus causing the company even further losses, is doing a favour for the other members of the pool. If successful, the claimant further solidifies the insurance company's promise to pay in case of accident, thereby also raising the value of the other insureds' policies.

The previous point leads to an important issue: It is essential to see insurance providers-be they private companies or welfare systems - as mediators through which pool members can find mutual solidarity; but without an additional component, this perspective would remain seriously deficient in view of insurance as a societal institution. This component is that insurers are not neutral mediators. Rather, they bring along their own interests, which are often to a great extent independent of individual insureds' interests. This is an important feature in discussions concerning the forms of exclusion and inequality that are evident in insurance, to which we turn next.

${ }^{8}$ Good overviews of the moral hazard and insurance literature are given by Baker (1996), Lesch and Baker (2013) and Stone (2002). 


\section{Constituting the insurance pool through inequalisation and exclusion}

Thus far, we have concentrated on issues concerning inclusion in an insurance pool and the related aspects of solidarity. On the backside of the matter, there are no universal pools, and, as even the most inclusive forms of social insurance are limited for citizens in certain countries or areas, all insurance is based on exclusion. Some insurance practices also produce inequality between those who can be included in the insurance community. But exclusion and inequality in insurance come in many forms and have heterogeneous reasons. In this section, we briefly trace some aspects of exclusion and inequality that characterise insurance practice.

Classically, the actuarial thinking behind insurance practice has relied on the idea that people can be treated as groups rather than individuals. Groups are formed according to general characteristics relevant to risk calculating, which enables the formation of risk pools where participants are somewhat equal. The private insurance industry particularly emphasises freedom of contract as the basis of the business; companies want to have the freedom to select which risks they underwrite and to distinguish between and group potential clients. Therefore, having groups pay different kinds of insurance premiums according to their differing risk levels has been considered legitimate. As Thiery and Van Schoubroeck have pointed out, this is in clear contrast to the 'human rights' perspective whereby people should not be discriminated against because they belong to a group, such as a racial, sexual, religious or ethnic group, to which they cannot negotiate their association (Thiery and Van Schoubroeck 2006, p. 195).

Thus, one form of inequality is related to the pricing of life, disability and health insurance products. As discussed in previous sections, if the initial risk or income differences are taken into account, and these differences are evened out in the name of solidarity, people are treated unequally from the actuarial fairness point of view. Vice versa, if the idea of actuarial fairness is strictly followed, pre-existing inequality based on risk and income differences is reinforced. Therefore, balancing these factors becomes an issue upon which decisions have to be made. One person's 'bad' is another person's 'good', and a choice is unavoidable. A decision between the options is irreducibly moral and political in nature, and it cannot rely on any objective external rule. From this emerges the understanding that, although insurance operates on technical calculations, these calculations are intimately dependent on political and moral stances. Therefore, insurance is fundamentally a moral and political technology. 
A second form of inequality or exclusion is when people are completely excluded from insurance pools. To regard national citizenship as a particular type of risk class highlights that, because there are no universal pools, the question concerning who can or must be included in a given pool is a political issue. First world nations have built their welfare systems for those who are included in the risk class comprising citizens of the nation-state, and the membership in such risk pools is often very favourable. Those left out of this class are deemed more uncertain risks, thus the reluctance to open the national welfare pool for incomers. In other words, those left out of insurance solidarity are forced to bear their risks alone, as individuals and households, in a situation where any kind of sharing would be advantageous. Again, insurance technology or the insurance form of social welfare is not at the origin of this inequality, but it reinforces, reproduces and transforms inequality.

Finally, that insurance pools usually create revenue complicates the discussions concerning solidarity, exclusion and inequality. An insurance contract is not simply a deal between pool members. Rather, the insuring institution also has a stake in the game. It might have an interest in minimizing indemnities and maximizing income gained from insurance fees and investing the money reserved for future liabilities. Crucial here is that the profits generated by the pool are not always shared equally, and pool members are sometimes completely excluded from them. Even when insureds are in solidarity, it is not given that the insurance provider as a third party plays fair or operates so that the customers' benefits are its main goal.

In this respect, the way the insurance institution is constituted is of major significance. Unlike stock corporations, mutual companies have no shareholders, and their funds are (primarily) built from premiums paid by policyholders. Thus, mutual companies do not pay dividends to external owners but divide the profits among policyholders who can also participate in the management of the company. In this way, social welfare systems based on insurance technology are very much like huge mutual companies. An important aspect is that, whereas a mutual company is at least in principle responsible to the insureds for its operations, a shareholder company usually sees the production of wealth for its owners as its primary function. The security and well-being of the company's clients is only of secondary importance. This situation is accentuated by the recent globalisation of financial flows and the related changes in the roles of the largest insurance companies. They are becoming increasingly detached institutions, and their functioning is becoming difficult to see in terms of mutual, shared responsibility accomplished by the insurance pool members. 


\section{Conclusion}

While we began this article with rather microscale considerations of people being prudent about their futures, we have ended with global financial flows. It is clear that the story could have been told in reverse order, in which case, the role of insurance business in global capitalism would have been more underlined. Perhaps a more critical view on the insurance industry would have emerged. We find this perspective legitimate, even necessary; however, in this article, we have sought to emphasise something else. That is, we have wanted to highlight how issues of solidarity are always and inevitably bound in insurance. However, as there is more than one form of solidarity relevant to insurance, the practices of insurance require decisions regarding the kinds of solidarity that are emphasised, when they are emphasised and on what grounds. In regard to questions concerning social justice it is especially significant that risk and income solidarity can be incompatible with the idea of 'actuarial fairness', which, for its part, is a major reference point for the insurance industry. Showing this internal tension within insurance solidarity reveals the inherently political and moral nature of insurance, regardless of whether it is organised privately or publicly.

Let us sum up the paper's main points. We have claimed, first, that insurance is clearly distinct from simple saving. The institutionalised and contractualised multipolarity it establishes between the members of an insurance pool and the service provider is crucial. Second, all forms of insurance (i.e. all forms of collectively preparing for future uncertainty by pooling resources and governing these pools by risk technologies) have to do with chance solidarity: No one knows in advance who will benefit from the pool, but through the insurance fees, all members participate in bearing the economic responsibility for harmful events the pool faces. This is a peculiar and distinct form of solidarity, as it is not, for instance, dependent on sentiments of mutuality or personal relationships.

Third, the existence of chance solidarity does not necessarily imply that the insurance relationship is experienced as fair. According to the idea of actuarial fairness, all members of the insurance pool pay according to the level of risk they transfer to the pool; that is, the ratio between risk and payment is equal for all. Despite its name, 'actuarial fairness' is often considered unfair. This is because the concept implies that those originally worse off in life pay much more than others. In this way, actuarial fairness reinforces previously existing inequalities and gives them new form. This is why the welfare systems — and some forms of private insurance-often apply also other forms of solidarity in addition to chance solidarity, by subsidizing those with high risk so they are not forced to pay according to their position on the insurance table (risk 
solidarity) or subsidizing those with lesser means so they can be included in the risk pools with lower fees than others (income solidarity).

Fourth, while there is always an element of solidarity in an insurance relationship, there is an element of inequality or exclusion as well. To begin with, there are unequal ways in which a pool member's risk level is considered in the determination of insurance premiums. In addition, people are sometimes excluded from insurance pools for seemingly unfair reasons. Finally, insurance providers can exclude insureds from the wealth generated by the pool. Mutual private insurance and statutory social insurance provide ways to avoid these exclusions. Nevertheless, this issue becomes increasingly important as the role of private insurance continues to grow in many countries and as insurance companies transform into huge global conglomerates whose primary raison d'être is to enrich shareholders, not to create security for the insureds who are in solidarity for having taken responsibility for one another's risks.

\section{Acknowledgements}

We would like to thank Xavier Landes for his comments and suggestions, which greatly improved the paper. The study was funded by the Helsinki Collegium for Advanced Studies, University of Helsinki, and the Academy of Finland (decision no. 28344). 


\section{Literature}

Barr, Nicholas. 2001. The welfare state as piggy bank. Information, risk, uncertainty, and the role of the state. Oxford: Oxford University Press.

Baker, Tom. 1994. Constructing the insurance relationship: Sales stories, claims stories, and insurance contract damages. Texas Law Review 72: 1395-1433.

Baker, Tom. 1996. On the genealogy of moral hazard. Texas Law Review 75: 237-292.

Baker, Tom. 2002. Risk, insurance, and the social construction of responsibility. In Embracing risk. The changing culture of insurance and responsibility, ed. Tom Baker and Jonathan Simon, 33-51. Chicago: University of Chicago Press.

Bayertz, Kurt. 1998. ed. Solidarität. Begriff und Problem. Frankfurt am Main: Suhrkamp.

Beveridge, William. 1942. Social insurance and allied services. London: His Majesty's Stationery Office.

Durkheim, Emile. 1984. The division of labor in society. New York: Free Press.

Ericson, Richard V., and Aaron Doyle. 2004. Uncertain business. Risk, insurance, and the limits of knowledge. Toronto: University of Toronto Press.

Ericson, Richard V., Aaron Doyle, and Dean Barry. 2003. Insurance as governance. Toronto: University of Toronto Press.

Ewald, François 1986. L'Etat providence. Paris: Bernard Grasset.

French, Shaun, and James Kneale. 2009. Excessive financialisation: Insuring lifestyles, enlivening subjects, and everyday spaces of biosocial excess. Environment and Planning D: Society and Space 27: 1030-1053.

Hacking, Ian. 1990. The taming of chance. Cambridge: Cambridge University Press.

Knoppers, Bartha Maria, Béatrice Godard, and Yann Joly. 2004. A comparative international overview. In Genetics and life insurance: Medical underwriting and social policy, ed. Mark A. Rothstein, 173-194. Cambridge, MA: MIT Press.

Landes, Xavier. 2014. How Fair Is Actuarial Fairness? Journal of Business Ethics 120: DOI 10.1007/s10551-014-2120-0.

Lehtonen, Turo-Kimmo. 2014. Picturing how life insurance matters. Journal of Cultural Economy 7: 308-333.

Lehtonen, Turo-Kimmo, and Jyri Liukko. 2010. Justifications for commodified security: The promotion of private life insurance in Finland 1945-1990. Acta Sociologica 53: 371-386.

Lehtonen, Turo-Kimmo, and Jyri Liukko. 2011. The forms and limits of insurance solidarity. Journal of Business Ethics 103: 33-44. 
Lesch, William C., and Brent R. Baker. 2013. Balancing the insurance equation: Understanding the climate for managing consumer insurance fraud and abuse. Journal of Insurance Issues 36: 82120.

Liukko, Jyri. 2010. Genetic discrimination, insurance, and solidarity: An analysis of the argumentation for fair risk classification. New Genetics and Society 29: 457-475.

Lobo-Guerrero, Luis. 2011. Insuring security: Biopolitics, security and risk. Routledge: Oxon.

Lobo-Guerrero, Luis. 2014. Life securitisation, the event object of insurance and the strategisation of time. Journal of Cultural Economy. doi: 10.1080/17530350.2013.858057

May, Larry. 1996. The socially responsive self. Social theory and professional ethics. Chicago: University of Chicago Press.

O'Malley, Pat. 2004. Risk, uncertainty and government. London: GlassHouse Press.

Rosanvallon, Pierre. 1995. La nouvelle question sociale. Paris: Seuil.

Spicker, Paul. 1991. Solidarity. In Towards a European welfare state, ed. Graham Room, 17-37.

Bristol: SAUS Publications.

Stjernø, Steinar. 2004. Solidarity in Europe. The history of an idea. Cambridge: Cambridge University Press.

Stone, Deborah. 2002. Beyond moral hazard: Insurance as moral opportunity. In Embracing risk. The changing culture of insurance and responsibility, ed. Tom Baker and Jonathan Simon, 52-79.

Chicago: University of Chicago Press.

Thiery, Yves, and Caroline Van Schoubroeck. 2006. Fairness and equality in insurance classification. The Geneva Papers 31: 190-211.

Van Hoyweghen, Ine. 2007. Risks in the making. Travels in life insurance and genetics. Amsterdam: Amsterdam University Press.

Van Hoyweghen, Ine, Klasien Horstman, and Rita Schepers. 2007. Genetic 'risk carriers' and lifestyle 'risk takers'. Which risks deserve our legal protection in insurance? Health Care Analysis 15: 179-193.

Zelizer, Viviana A. Rotman. 1983. Morals and markets. The development of life insurance in the United States. New Brunswick and London: Transaction Books. 